\title{
Reflets
}

Revue ontaroise d'intervention sociale et communautaire

\section{Expérience spirituelle}

Témoignage de Ronald Maltais

\section{Ronald Maltais}

Volume 12, numéro 1, 2006

Spiritualité et intervention sociale

URI : https://id.erudit.org/iderudit/013446ar

DOI : https://doi.org/10.7202/013446ar

Aller au sommaire du numéro

Éditeur(s)

Reflets : Revue ontaroise d'intervention sociale et communautaire

ISSN

1203-4576 (imprimé)

1712-8498 (numérique)

Découvrir la revue

Citer cet article

Maltais, R. (2006). Expérience spirituelle : témoignage de Ronald Maltais.

Reflets, 12(1), 197-200. https://doi.org/10.7202/013446ar

Tous droits réservés (C) Reflets : Revue ontaroise d'intervention sociale et communautaire, 2006

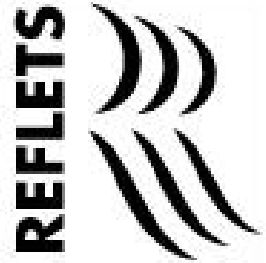

Ce document est protégé par la loi sur le droit d'auteur. L'utilisation des services d'Érudit (y compris la reproduction) est assujettie à sa politique d'utilisation que vous pouvez consulter en ligne.

https://apropos.erudit.org/fr/usagers/politique-dutilisation/ 


\section{Expérience spirituelle}

Témoignage de Ronald Maltais

Travailleur social

J'ai grandi, pendant les années 60 , dans une petite ville du nord du Nouveau-Brunswick où j'ai reçu de ma famille et du système scolaire une éducation religieuse axée sur le catéchisme catholique romain; il faut bien dire que cela avait très peu de liens avec les enseignements de l'Ancien et du Nouveau Testament tels que je les connais maintenant. Je vivais dans une société fermée. La messe en était un exemple : elle se célébrait en latin.

Toutefois, les suicides manqués de ma sœur et de mon cousin et les épisodes psychiatriques de trois de mes sœurs semèrent la confusion dans notre vie familiale. La mort et la psychiatrie frappèrent à la porte de nos cœurs déchirés et désemparés. Sans connaitre Durkheim, nous rendîmes visite au psychiatre. Pour ma part, mon dossier médical était empreint de maladie. Naissance prématurée, fièvre scarlatine, strabisme, surdité, syndrome de Gilles de la Tourette et, plus tard, dépression et alcoolisme. Cet état de santé m'a conduit, en 2003, à un statut d'invalidité auquel je me résigne avec une certaine sérénité.

Ma vie familiale a été marquée par l'adversité : père alcoolique, mère battue, deux de mes sœurs frappées par la schizophrénie et une par la dépression.

Durant ma préadolescence, je me demandais pourquoi l'homme des cavernes nous laissa savoir qu'il croyait dans une vie après la mort. D'où venait le sens du sacré dans cet âge de l'histoire de l'humanité? Plus je lisais ma revue préférée, le National Geographic, plus je découvrais cette croyance, enracinée à la fois chez les pharaons en Égypte et chez les Amérindiens. Dès l'adolescence, j'entreprends une quête 
remplie de réveils spirituels qui vont nourrir ce sens inné du sacré.Au cours de cette période, je fais face à plusieurs défis : la révolution sexuelle, la révolution féministe, la Révolution tranquille au Québec, des manifestations contre la guerre du Vietnam, la révolution technologique, la conquête de l'espace, et j'en passe.

Toutes ces révolutions sociales créent une société laïque qui se détache de l'empire des clercs catholiques romains pour s'ouvrir au monde entier, mais aussi au monde intérieur. Je sens un vent venu de l'Orient et je découvre le mantra d'une méditation transcendantale. Avec la répétition de ce mantra, un vide mental s'effectue dans mon esprit et je rebondis d'énergie. Depuis, cet attrait pour les religions et les philosophies orientales imprègne ma vie, motive ma recherche d'être.

Au cours de mon baccalauréat en service social à l'Université de Moncton, toujours fasciné par le sacré indépendant des dogmes et des églises, je me mets à la pratique de la méditation par la voie du cœur du maitre spirituel Sri Chinmoy. Dès la première rencontre, je fixe mon regard sur le "troisième oil " de la photo du maitre et je respire autrement; à mon insu, mon corps réagit et je sens une énergie centrée sur mon coeur.

Il y a bel et bien une expérience spéciale, intime et sacrée, qui va me marquer tant dans mon cheminement spirituel que personnel puisque, plus je lis l'œuvre de ce maitre réalisé, plus je développe une conception à la fois paternelle et maternelle de Dieu.Aussi,je réalise que je ne connais pas mon héritage pagano-chrétien, soit l'Ancien et le Nouveau Testament, et je dois avouer que j'ai peur du concept de la réincarnation; pourtant, je suis familier avec le concept du bardot du Livre des morts tibétains. Fort de mes croyances chrétiennes, je me sens plus à l'aise avec l'idée d'une résurrection.J'entreprends donc le cours de catéchèse Messe Association Jésus Église où je redécouvre mon héritage chrétien. 
À l'âge de 41 ans, je constate une dépendance sévère à l'alcool et je découvre le programme des douze étapes. Je me mets à prier pour mon problème de boisson, mon problème de nerfs et mon problème de solitude souffrante. Il s'agit d'un second réveil spirituel grâce auquel je reçois bien plus que la sobriété : la sérénité.

En cours de route, un ami me suggère de lire La variété des expériences religieuses de William James. « La religion, pour celui-ci, va signifier les sentiments, les actes, et les expériences humaines, qui, dans leur solitude, appréhendent être en relation avec le Divin " (1997:31).

Trois crises m'ont donc signalé que ma vie personnelle et familiale était en souffrance. La maladie et la pauvreté constituent à elles seules des maîtres qui obligent le retour sur soi et la remise en question de nos valeurs d'avoir, des buts de notre existence, de nos liens avec l'au-delà.

Depuis mon jeune âge, un étrange soliloque et des cris stridents m'isolent dans la prison de la folie. Accouplée à la peur de la folie, se manifeste la peur de la pauvreté, en plus d'une crise d'identité aiguë. Cette crise a duré seize ans, jusqu'au jour où un psychiatre pose le diagnostic du syndrome de Gilles de la Tourette.

Je n'ai alors d'autre choix que de faire un examen de ma vie personnelle, familiale et sociale et je sombre dans l'alcoolisme. Heureusement que j'ai eu comme compas la recherche de Dieu et mon programme spirituel des douze étapes qui m'ont aidé à m'accrocher à la vie en m'amenant à prier et à écrire ma souffrance; Dieu me délivre de toutes mes peurs et angoisses.

Finalement, après vingt-cinq ans de difficiles combats personnels et familiaux, la santé est revenue dans ma famille. Je remarque que la prière a pris la place qui lui revenait. Mes soeurs et moi nous acceptons nos passés et nous nous entraidons. "Accepter la vie pour transformer la vie à l'heure choisie de Dieu et selon la manière de Dieu " (Sri Chinmoy : 1). 
Si j'ai résolu mes problèmes, c'est que la vie m'a enseigné que tout passait par l'acceptation. Les travailleurs sociaux savent très bien que les pauvres prient et méditent. Le programme des douze étapes pourrait bien s'intégrer à leur pratique.

De toute cette histoire, la seule synthèse que je puisse effectuer à la lumière d'un cheminement spirituel personnel consiste à constater que Dieu est une énergie sacrée, à la fois paternelle et maternelle, très amoureuse de nous. La clé du cœur ouvre la porte à sa présence. En ce sens, la vie est une retraite et les épreuves sont des occasions d'apprendre davantage sur nous, sur les gens qui nous entourent et sur notre potentiel humain.

\section{Bibliographie}

William James (1997). Varieties of Religious Experiences, New York, Simon \& Schuster. Sri Chinmoy (1998). Le voyage de l'âme, Éditions La Flûte d'or, Paris. 